\title{
The collateral network concept: A reassessment of the anatomy of spinal cord perfusion
}

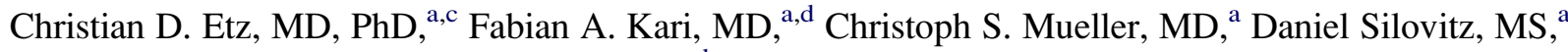 \\ Robert M. Brenner, MS, ${ }^{a}$ Hung-Mo Lin, $\mathrm{PhD},{ }^{b}$ and Randall B. Griepp, MD ${ }^{\mathrm{a}}$
}

\begin{abstract}
Objective: Prevention of paraplegia after repair of thoracoabdominal aortic aneurysm requires understanding the anatomy and physiology of the spinal cord blood supply. Recent laboratory studies and clinical observations suggest that a robust collateral network must exist to explain preservation of spinal cord perfusion when segmental vessels are interrupted. An anatomic study was undertaken.
\end{abstract}

\begin{abstract}
Methods: Twelve juvenile Yorkshire pigs underwent aortic cannulation and infusion of a low-viscosity acrylic resin at physiologic pressures. After curing of the resin and digestion of all organic tissue, the anatomy of the blood supply to the spinal cord was studied grossly and with light and electron microscopy.
\end{abstract}

\begin{abstract}
Results: All vascular structures at least $8 \mu \mathrm{m}$ in diameter were preserved. Thoracic and lumbar segmental arteries give rise not only to the anterior spinal artery but to an extensive paraspinous network feeding the erector spinae, iliopsoas, and associated muscles. The anterior spinal artery, mean diameter $134 \pm 20 \mu \mathrm{m}$, is connected at multiple points to repetitive circular epidural arteries with mean diameters of $150 \pm 26 \mu \mathrm{m}$. The capacity of the paraspinous muscular network is 25 -fold the capacity of the circular epidural arterial network and anterior spinal artery combined. Extensive arterial collateralization is apparent between the intraspinal and paraspinous networks, and within each network. Only $75 \%$ of all segmental arteries provide direct anterior spinal artery-supplying branches.

Conclusions: The anterior spinal artery is only one component of an extensive paraspinous and intraspinal collateral vascular network. This network provides an anatomic explanation of the physiological resiliency of spinal cord perfusion when segmental arteries are sacrificed during thoracoabdominal aortic aneurysm repair. (J Thorac Cardiovasc Surg 2011;141:1020-8)
\end{abstract}

A thorough understanding of the anatomy of the blood supply of the spinal cord appears essential for developing optimal strategies to prevent spinal cord injury during and after open surgical or endovascular repair of extensive thoracic and thoracoabdominal aortic aneurysms (TAAAs). Direct visualization of these vessels is difficult clinically, ${ }^{1-5}$ however, and most surgeons therefore continue to rely on descriptions of the spinal cord circulation derived from a few classic anatomic studies. ${ }^{6-8}$ The most influential of these has been the treatise by Albert W. Adamkiewicz (1850-1921), whose meticulously detailed and beautiful drawings suggest that the most important input into the anterior spinal artery (ASA) is a single dominant branch of a segmental artery

From the Department of Cardiothoracic Surgery, ${ }^{a}$ the Department of Anesthesiology/ Division of Biostatistics, ${ }^{\mathrm{b}}$ Mount Sinai School of Medicine, New York, NY; Department of Cardiac Surgery, ${ }^{c}$ Heartcenter, Leipzig University, Leipzig, Germany; and Department of Cardiovascular Surgery, ${ }^{\mathrm{d}}$ Cardiovascular Center, University Hospital Freiburg, Freiburg, Germany.

Supported by grant HL045636 from the National Heart, Lung and Blood Institute.

Disclosures: Authors have nothing to disclose with regard to commercial support.

Received for publication April 13, 2010; revisions received May 25, 2010; accepted

for publication June 9, 2010.

Address for reprints: Randall B. Griepp, MD, Mount Sinai School of Medicine, Department of Cardiothoracic Surgery, One Gustave L. Levy Pl, PO Box 1028,

New York, NY 10029 (E-mail: randall.griepp@mountsinai.org).

$0022-5223 / \$ 36.00$

Copyright (c) 2011 by The American Association for Thoracic Surgery doi: 10.1016/j.jtcvs.2010.06.023
(SA) in the lower thoracic or upper lumbar region with a characteristic hairpin turn, which is now often referred to as the artery of Adamkiewicz. ${ }^{9}$

The consensus has been that identification and then reimplantation of the SA supporting this important artery during repair of TAAA is the best possible strategy for preserving spinal cord blood supply and thereby preventing paraplegia or paraparesis. ${ }^{1,2,4,10-12}$ Despite various painstaking and inventive techniques to avoid spinal cord injury with this approach, there continues to be a definite seemingly irreducible incidence of paraplegia and paraparesis after treatment of extensive TAAAs. ${ }^{4,12-14}$ Furthermore, reattaching the artery of Adamkiewicz or other large intercostal or lumbar arteries-already a daunting undertaking during open surgical repair-is not really possible with current endovascular techniques. Thus the combined incentives of trying to avoid the rare but devastating occurrence of paraplegia after surgical repair of extensive TAAAs, and the appealing future prospect for their treatment, make it seem reasonable to reassess our understanding of the spinal cord circulation with the aim of developing a strategy to ensure postoperative spinal cord perfusion adequate to prevent paraplegia without reattaching SAs. ${ }^{15,16}$

We therefore undertook a series of anatomic explorations in the pig, which previous studies have documented has a spinal cord circulation very similar in its physiologic responses 


\section{Abbreviations and Acronyms \\ ARMA $=$ anterior radiculomedullary artery \\ ASA $=$ anterior spinal artery \\ SA $=$ segmental artery \\ SEM = scanning electron microscopy \\ TAAA $=$ thoracoabdominal aortic aneurysm}

to that of human beings. These anatomic studies, described here for the first time in detail, establish the presence of an extensive collateral network that supports spinal cord perfusion. Our anatomic findings buttress previous clinical and experimental observations that have suggested the presence of such a network in both human beings and pigs. ${ }^{16-18}$

Putting together all our evidence to date, the collateral system involves an extensive axial arterial network in the spinal canal, the paravertebral tissues, and the paraspinous muscles, in which vessels anastomose with one another and with the nutrient arteries of the spinal cord. ${ }^{19}$ The configuration of the arterial network -in both in human beings and pigs-includes inputs not only from the segmental vessels (intercostals and lumbars) but also from the subclavian and the hypogastric arteries. ${ }^{20}$ The presence of this extensive network implies a considerable reserve to ensure spinal cord perfusion when some inputs are compromised but also presents opportunities for vascular steal. The aim of this study is to describe the collateral network in sufficient detail to allow appreciation of its potential benefits as well as vulnerabilities to lay a sound foundation for development of strategies to prevent paraplegia after TAAA repair.

\section{MATERIALS AND METHODS}

Twelve female juvenile Yorkshire pigs (Animal Biotech Industries, Allentown, $\mathrm{NJ}$ ) weighing $12 \pm 2 \mathrm{~kg}$ (range, $10-13 \mathrm{~kg}$ ) underwent standard aortic cannulation and total body perfusion with a low-viscosity acrylic resin $(800$ mL, Batson's No. 17, Anatomical Corrosion Kit; Polysciences Inc, Warrington, Pa) to create a vascular cast of the circulation. Perfusion was carried out with extracorporeal circulation (the cardiopulmonary bypass circuit without an oxygenator) at physiologic pressures with pulsatile flow to achieve filling of all vessels, including the capillaries.

As has previously been described, the pig differs anatomically from human beings in having 13 thoracic vertebrae. The first 3 thoracic SAs are branches of the left subclavian; the subsequent 10 thoracic and 5 lumbar arteries arise together from the aorta and then divide..$^{20,21}$ Previous studies suggest that the subclavian arteries and the median sacral arteries each play a major role in the perfusion of the paraspinous collateral vascular network in both species, although the iliac arteries may provide a greater proportion of the direct blood supply in human beings than in pigs. ${ }^{20}$ Previous experiments with this model have demonstrated that spinal cord perfusion pressure and collateral flow in the pig behave in ways very similar to those observed clinically under comparable circumstances in human beings. ${ }^{18,22,23}$

After curing of the resin and digestion of all organic tissue as described, the anatomy of the blood supply to the spinal cord was studied grossly and in detail with light microscopy and scanning electron microscopy (SEM), with special attention to its interconnections with the vasculature of adjacent muscles. To visualize vessels contributing to the blood supply of the spinal cord and for better comparison of the porcine vascular cast with human anatomy, selected vascular casts were scanned and processed for 3-dimensional image reconstruction in a computed tomographic scanner.

\section{Perioperative Management and Anesthesia}

All animals received humane care in compliance with the guidelines of Principles of Laboratory Animal Care formulated by the National Society for Medical Research and the Guide for the Care and Use of Laboratory Animals published by the National Institutes of Health (NIH Publication No. 88-23, revised 1996, www.nap.edu/catalog/5140.html). The Mount Sinai institutional animal care and use committee approved the protocols for all experiments.

After pretreatment with intramuscular ketamine $(15 \mathrm{mg} / \mathrm{kg})$ and atropine $(0.03 \mathrm{mg} / \mathrm{kg})$, an endotracheal tube was placed. The animals were then transferred to the operating room and were mechanically ventilated. Anesthesia was induced and maintained as described previously ${ }^{18} \mathrm{An}$ arterial line was placed in the right brachial artery for pressure monitoring before and during resin perfusion.

\section{Operative Technique and Acrylic Resin Perfusion}

The chest was opened through a small left thoracotomy in the fourth intercostal space. The pericardium was opened, and the heart and great vessels were identified. After heparinization ( $300 \mathrm{IU} / \mathrm{kg}$ ), the right atrium was cannulated with a 26F single-stage cannula, and the aortic arch was cannulated with a 16F arterial cannula. The cardiopulmonary bypass circuit consisted of roller heads without an oxygenator and heat exchanger. The animal was perfused and blood washout was accomplished with $1800 \mathrm{~mL} 0.9 \%$ saline solution and $4000 \mathrm{IU}$ heparin. The reservoir of the pump was then loaded with low-viscosity acrylic resin. After a clamp had been placed across the proximal ascending aorta to prevent leakage of resin across the aortic valve, whole-body perfusion was started at physiologic pressures while exsanguination was achieved through the venous cannula. Perfusion pressures were monitored through a right axillary catheter and a pressure line connected to the aortic inflow tubing. Peak pressure was 120 to $130 \mathrm{~mm} \mathrm{Hg}$, achieving complete filling of all vascular structures at least $8 \mu \mathrm{m}$ in diameter. The pump was stopped and the lines were clamped after the concentration of the acrylic resin in the right atrium reached $80 \%$.

\section{Cast Processing}

The resin was allowed to cure for 24 hours at room temperature. Thereafter the paraspinous structures were dissected en bloc, preserving all spinal and paraspinous bony, muscular, and central nervous tissues. All organic tissue was dissolved in a bath of $10 \mathrm{~N}$ potassium hydroxide solution in specially designed tubs with an active stirring device to accelerate tissue dissolution. During the next 3 to 7 days, the acrylic casts were removed daily from the potassium hydroxide bath, and organic debris was carefully removed before reimmersion. At the end of the cleaning process, all casts underwent multistep analysis.

\section{Cast Analysis}

The anatomy of the spinal cord blood supply and its connections with the vasculature of adjacent muscles was investigated grossly and with light microscopy and SEM. Each cast was analyzed with focus on the axial arterial network within the spinal canal and in the paraspinous muscles. Collateral anastomoses were identified and the vessel network described in detail, quantifying vessel volumes and diameters.

Light microscopy. For visualization of the intraspinal vascular structures, the spinal canal was exposed by removing the dorsal processes and washing the intraspinal portion of the cast. Images of the intraspinal vessels (ASA and epidural arcades) were obtained at every segmental level. The digital image files were used for measurements of intraspinal vessel diameters with ImageTool 3.0 image analysis software (University of Texas Health Science Center at San Antonio, San Antonio, Tex). 


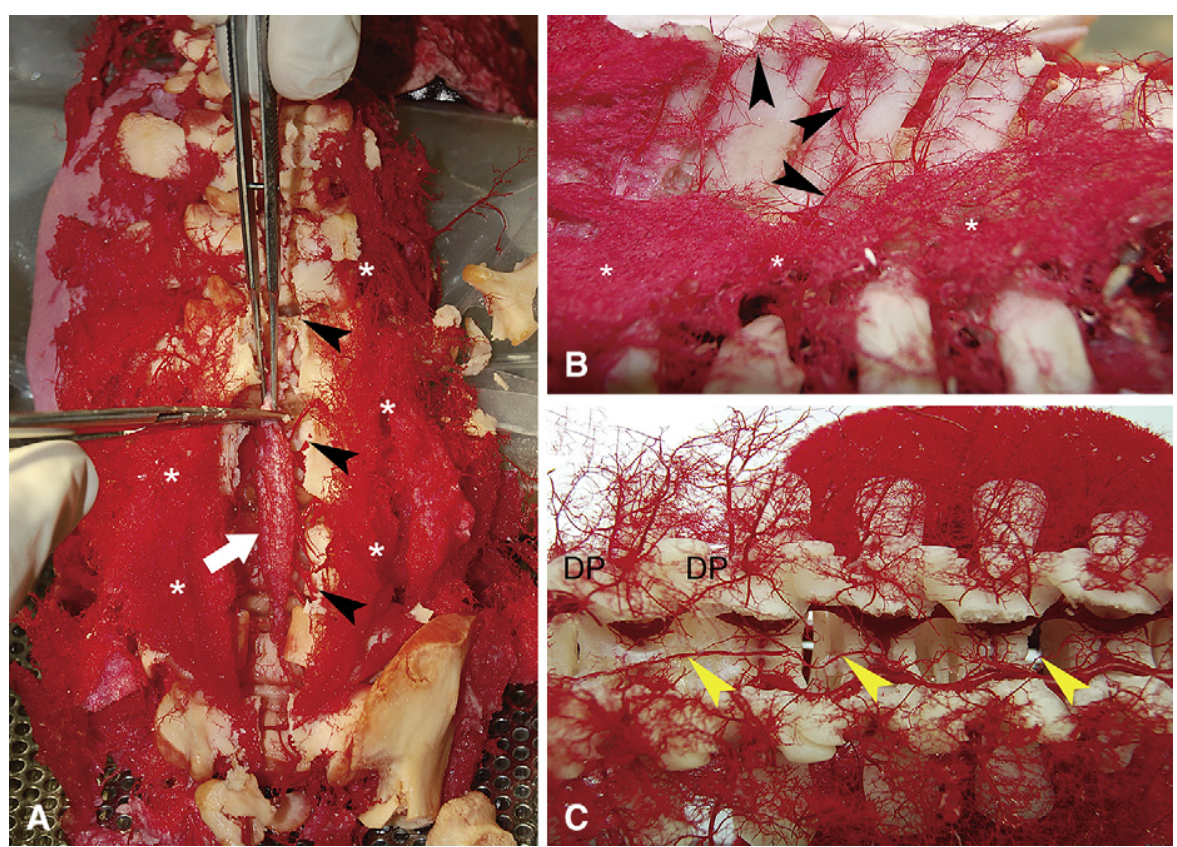

FIGURE 1. Processing of an acrylic cast. A, After the soft tissue maceration and multiple cleaning steps with distilled water, the spinal canal (black arrows) is opened dorsally by cutting pedicles of vertebrae. Casts of spinal cord arteries (white arrow lower lumbar cord) are dissected and freed from neural and glial tissues. Asterisks indicate the vessels of the lower paraspinous musculature. B, Lateral view of casts of vessels along dorsal processes shows paravertebral extramuscular arcades consisting of arterioles that interconnect segmental levels longitudinally (black arrowheads). Asterisks indicate the extensive vasculature of the paraspinous muscles. C, Dorsal view of the opened spinal canal onto the lower thoracic (left) and upper lumbar (right) segments. Yellow arrows show the anterior spinal artery. $D P$, Distribution points of single dorsal segmental arteries, where the dorsal main stem divides into the extensive muscular paraspinous vascular tree, giving rise to different intraspinal branches.

Scanning electron microscopy. A scanning electron microscope (Hitachi S 4300 cold field SEM; Hitachi High Technologies America, Inc, Schaumburg, Ill) was used to visualize the microstructure of the arterial network. Each sample was cleaned in a warm distilled water bath to remove organic remnants and calcium for a minimum of 10 days before gold coating for SEM with a Technics Hummer V Sputter Coater (Stanford Nanofabrication Facility, Stanford, Calif).

SEM imaging data were systematically acquired and subjected to morphometric study with ImageTool 3.0 image analysis software. Angio computed tomographic scanning and 3-dimensional reconstructions of selected casts allowed digital processing and collection of data regarding spatial configuration. The studies were designed to enable accurate quantification of the configuration and capacity of the vascular network supplying both the spinal cord and the muscles and other tissues adjacent to it.

Quantification of cast volumes. For evaluation of blood volume distribution among the different collateral systems (intraspinal, paraspinal) of a single SA, 5 nonadjacent segments that were representative in their macroscopic appearance and had optimal perfusion results were dissected from the cast tissue block. Cast volume was calculated from cast weight and resin density (density of Batson's No. 17 resin is $1.18 \mathrm{~g} / \mathrm{mL}$, calculated by polymerized resin block). The cast of the paraspinous vascular tree was separated from all vessels directly supplying the anterior spinal circulation (anterior radiculomedullary arteries [ARMAs]) and the epidural arcades. Intraspinal and extraspinal cast volumes were calculated by weighing each of the different parts of the disassembled vascular model.

SEM quantification of vessel diameter distribution. For morphometric analysis of the vascular networks, an overview image $(\times 80)$ was used to identify representative areas of the vascular cast specimen with good perfusion. Pictures were taken of these areas at various magnifications $(\times 100, \times 200, \times 400)$. All image data were stored as digital files and processed for morphometric analysis. Contrast within each image file was adjusted to achieve optimal visualization of as many vessels as possible. A counting grid ( 35 single squares, $0.034 \mathrm{~mm}^{2}$ each, images $\times 100$ ) was projected onto the original image file with $\mathrm{x}$ - and $\mathrm{y}$-axes in every square (Adobe Photoshop CS 2; Adobe Systems Inc, San Jose, Calif). The grid was used for spatial orientation within the image and to ensure an even and random distribution of measurements. The vessels to be measured were chosen from lists of random numbers used as coordinates within the counting grid. Two measurements per square were analyzed with ImageTool 3.0 image analysis software.

Arterial vessels were identified according to SEM morphologic criteria defining arterioles as sharply demarcated and longitudinally oriented endothelial nuclear imprints, oval in shape. The distribution of the measured vessel diameters within the paraspinous networks was systematically assessed.

\section{Statistical Methods}

Data were entered in an Excel spreadsheet (Microsoft Corp, Redmond, Wash) and transferred to an SAS file (SAS Institute Inc, Cary, NC) for data description and analysis; data are described as percentage, median with range, or mean $\pm \mathrm{SD}$.

\section{RESULTS}

The vascular system supplying the spinal cord (including SAs, ARMAs, and the ASA) and its adjacent tissues (including the vertebrae and the erector spinae and psoas muscles) was cast in its entirety in each animal (Figures 1 and 2). The polymeric resin reached networks of small arterioles, capillaries (with diameters less than $7 \mu \mathrm{m}$ ), and venules. 


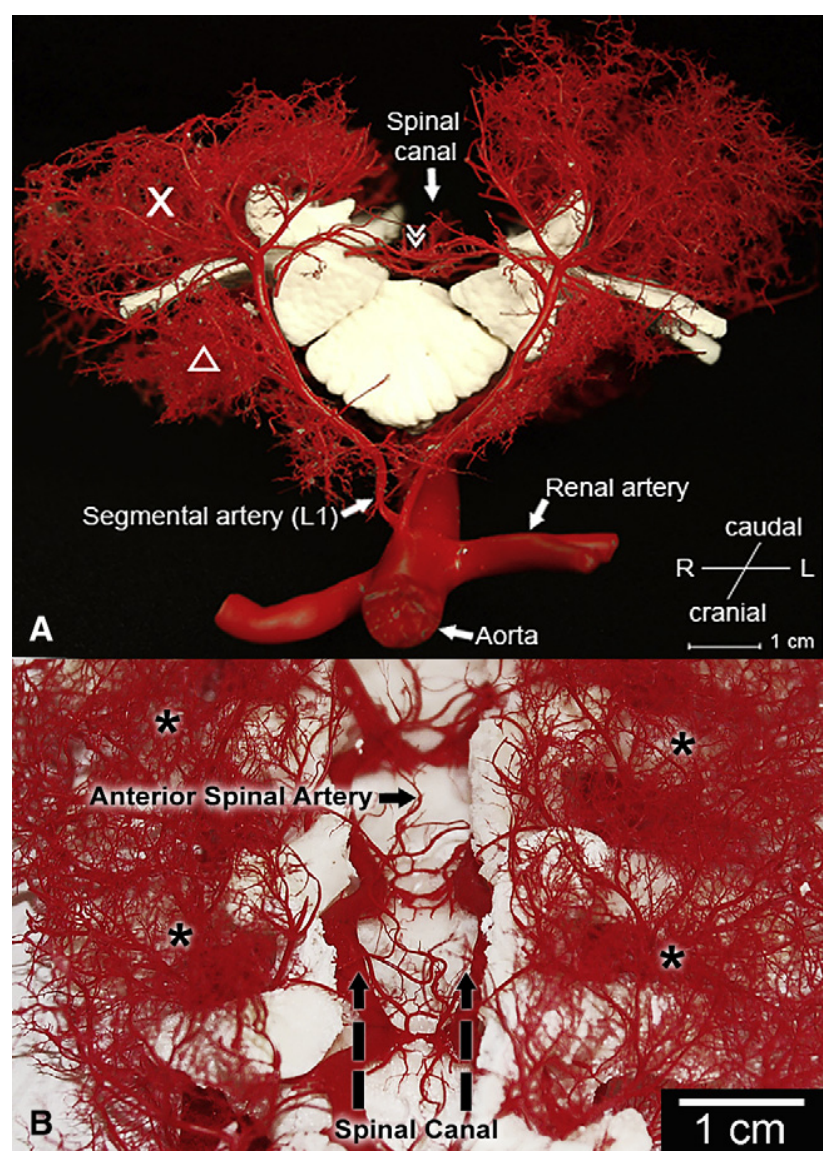

FIGURE 2. Anatomy of the collateral network, sagittal (A) and dorsal (B) views. Macroscopic appearance of the pair of dorsal segmental vessels at L1. The dorsal process is removed. In $\mathrm{A}$, the $X$ designates the paraspinous muscular vasculature providing extensive longitudinal arterioarteriolar connections in A and B; the triangle indicates iliopsoas muscle; the double arrow indicates anterior spinal artery.

\section{Thoracic and Lumbar SAs and Types of Intersegmental Connections}

The thoracic and lumbar SAs give rise to 3 major vessel groups, which anastomose extensively within each group and with one another (Figures 2 and 3). The first group consists of the intrathecal vessels: the ASA and a longitudinal chain of epidural arcades lying between the spinal cord and the vertebral bodies (Figures 2 and 3). The second is a group of interconnecting vessels lying outside the spinal canal along the dorsal processes of the vertebral bodies (Figure 1). The third is a massive collection of interconnecting vessels supplying the paraspinous muscles, including the iliopsoas anteriorly and the erector spinae posteriorly.

\section{Intrathecal Vessels (Figures 3 and 4)}

The intrathecal vessels consist of the ASA, with an average diameter of $134.0 \pm 20 \mu \mathrm{m}$, and the epidural arcades, which have a mean diameter of $150.0 \pm 26 \mu \mathrm{m}$. The ASA

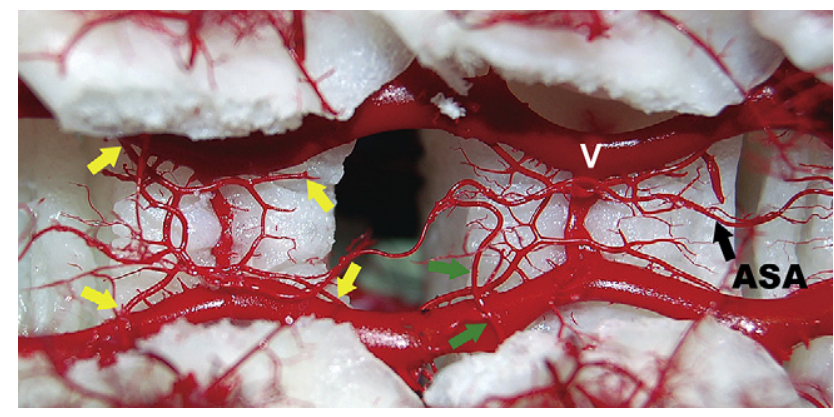

FIGURE 3. Relationship of the anterior spinal artery $(A S A)$ and the repetitive epidural arcades. The dorsal view into the opened spinal canal showing the dorsal surface of 2 vertebral bodies. The spinal cord is removed to clarify anatomic location of the epidural circular arcades and the anterior spinal artery. $V$ indicates the epidural venous plexus. Anterior to the extensive venous plexus, 4 arteriolar branches (yellow arrows) contribute to 1 circular epidural arcade. This pattern is repeated at level of each vertebral segment. These vascular structures connect segments side to side as well as longitudinally. They connect with the main stems of segmental arteries and can therefore be considered to contribute indirectly to anterior spinal artery. Green arrows designate the anterior radiculomedullary artery, which connects directly with the anterior spinal artery.

is supplied primarily by the ARMAs, filled principally by the left-sided branches of the SAs, with $60 \%$ of the SAs in the thorax and $82 \%$ in the lumbar region providing a direct branch to the ASA.

The epidural arcades consist of a series of circular or polygonal structures at the level of each vertebral body. They form a longitudinal as well as a side-to-side anastomotic network and connect extensively to the ASA by way of the ARMAs and branch points from the SAs. Branches from the segmental vessels to the arcades are present at each level from both sides. The combined volume of all the intrathecal vessels - the ASA, the epidural arcades, and the connecting vessels—is $5 \mu \mathrm{L} /$ segment.

\section{Extrathecal Vessels}

The first group of extrathecal vessels consists primarily of small branches of the dorsal limbs of the SAs. It is not possible to separate these branches distinctly from the muscular vessels, except for the fact that they are particularly rich in connections along the long axis of the spine and also from one side to the other around and posterior to the spinous processes of the vertebral bodies. The plexus of interconnected vessels within the paraspinous muscles-including the iliopsoas anteriorly and the erector spinae and assorted muscles posteriorly (quadratus lumborum, ileocostalis lumborum, longissimus thoracis) - dominate the segmental circulation (Figure 2). The volume of these extrathecal vessels is 125 $\mu \mathrm{L} /$ segment, 25-fold that of the intrathecal vessels.

The microanatomy of the intramuscular network is depicted in Figures 5 and 6. Arteries and arterioles, veins and venules, and capillaries can be readily distinguished from

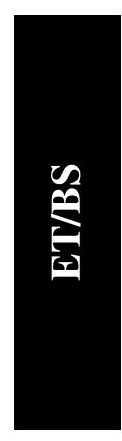




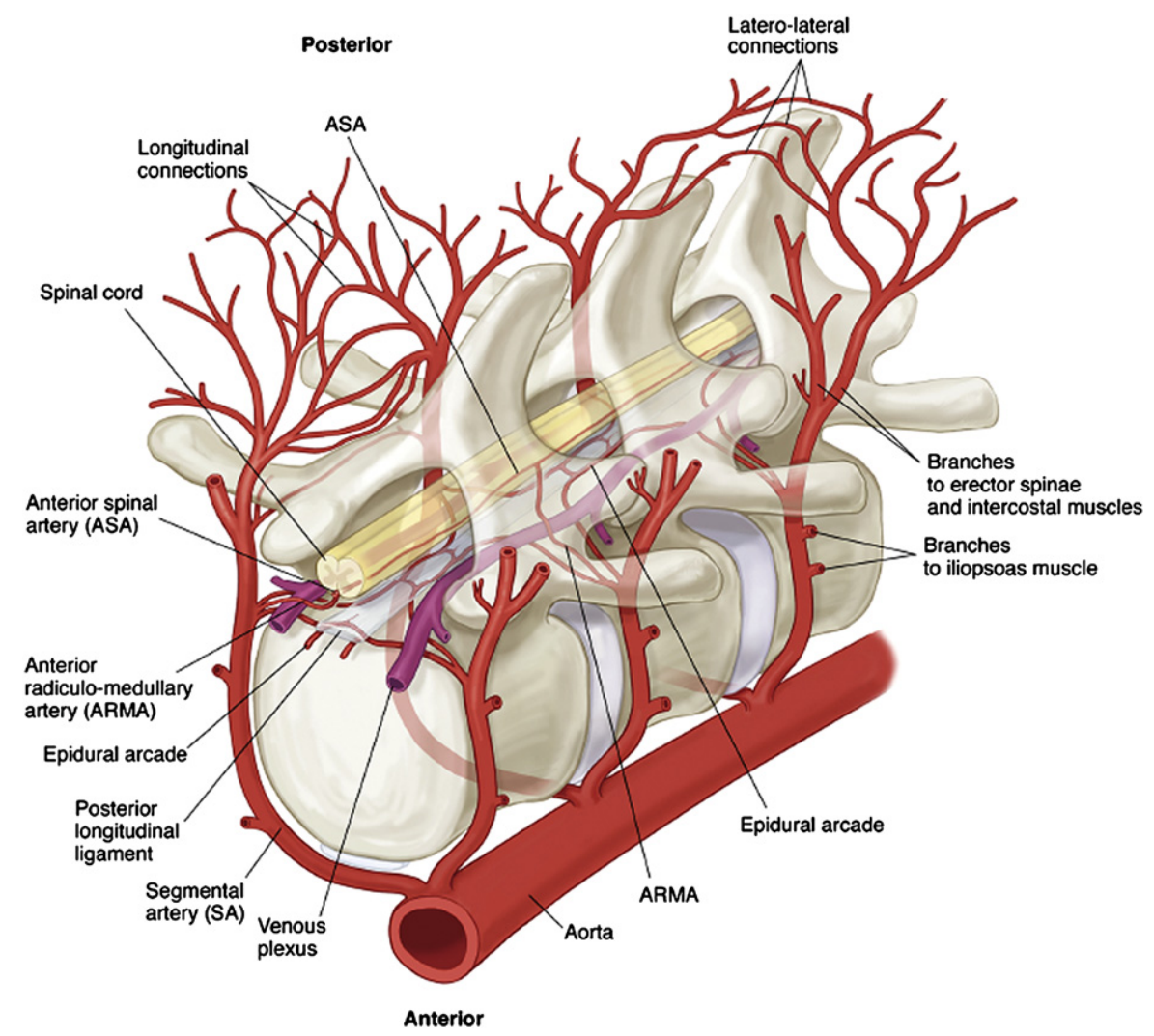

FIGURE 4. A schematic diagram of the blood supply to the spinal cord demonstrates the relationships, relative sizes, and the interconnections among the segmental arteries $(S A s)$, the anterior radiculomedullary arteries (ARMAs), the epidural arcades, and the anterior spinal artery (ASA). The longitudinal anastomoses along the dorsal processes of spine as well as dorsal communications (interstitial connections) between the right and the left branches of segmental arteries are also shown.

each other (and from perfusion artifacts). The predominant arterial structures are arterioles between 10 and $40 \mu \mathrm{m}$ in diameter (Figure 5). The vessels most frequently encountered overall are capillaries, vessels less than $10 \mu \mathrm{m}$ in diameter (Figure 7). Because the emphasis of this study was on the arterial blood supply of the cord, veins and venules were not quantified.

\section{DISCUSSION}

The studies described in this report provide a more detailed anatomic basis than has heretofore been available to substantiate what we have previously described as the collateral network hypothesis of spinal cord blood flow, chiefly on the basis of physiologic observations in both human beings and pigs. ${ }^{17}$ The cast studies demonstrate quite dramatically that the previously hypothesized collateral network includes the SAs and the spinal cord circulation but is dominated by the much more extensive dense, rich vasculature of the paraspinous muscles. It shows that the arteries to the spinal cord, the muscles, and the other paravertebral tissues are all interconnected, with multiple longitudinal anastomoses all along the vertebral column.
Although these studies were purely anatomic and were carried out in young pigs for practical reasons, their relevance to the clinical situation is supported by numerous previous physiologic studies in which patterns of response in the pig model have proved remarkably similar to observations in patients with aortic disease. ${ }^{16,24}$ The human spinal cord circulation, outlined by quite similar techniques in the commercial exhibit Bodies shows a convincingly close resemblance to these pig cast studies; however, images from that exhibit cannot be published. In 1976, Crock and colleagues $^{25}$ published the results of an anatomic cadaver study describing the arterial supply to the vertebral column, cord, and nerve roots in human beings. Parallels can be drawn between the human and the porcine segmental blood supply and collateralization when comparing our results with the results described by Crock and colleagues. ${ }^{25}$ For example, as is only briefly described in that article, a repetitive ring-shaped arterial pattern on the dorsal surface of the vertebral bodies is present in human beings as well as in pigs; however, it has hardly been noted before and has not been systematically described as a possibly vital part of a backup system to restore flow to the cord after loss of direct segmental inflow. Although it can be argued that the collateral 


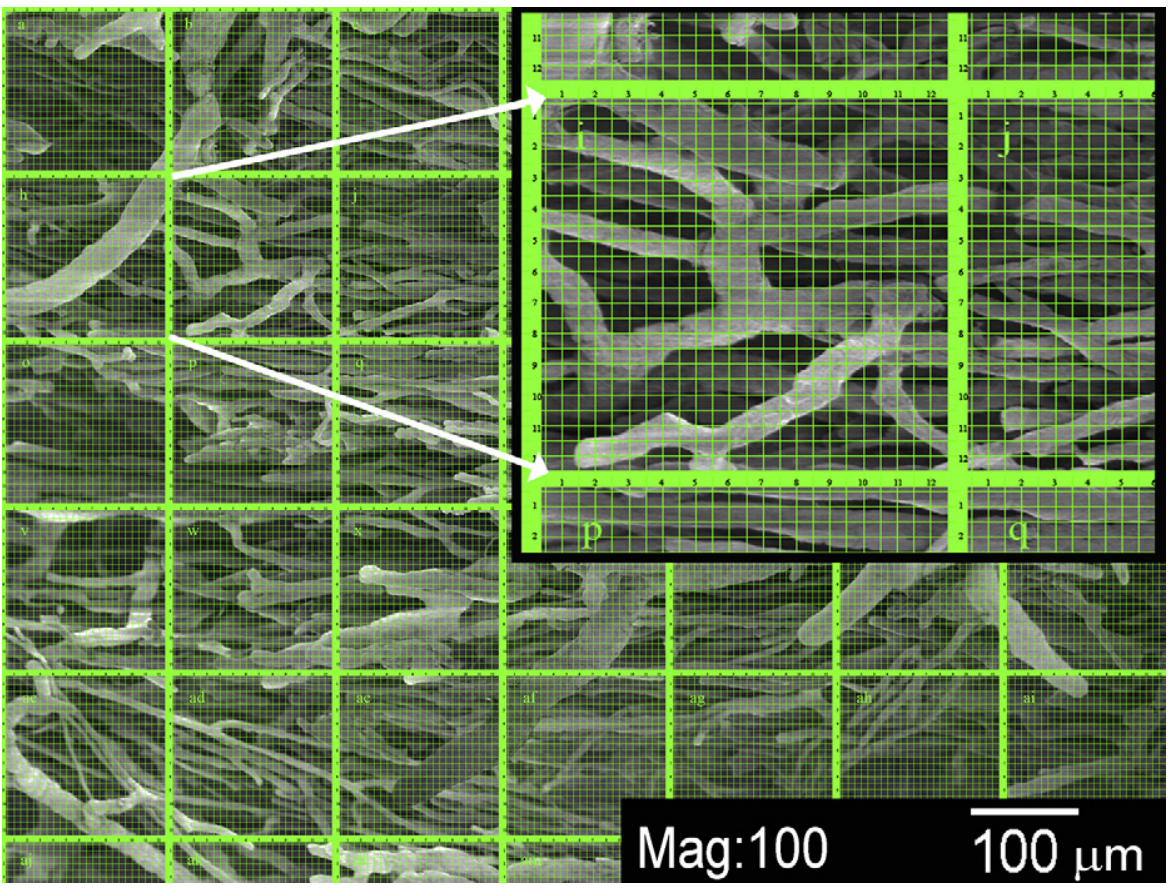

FIGURE 5. Cast analysis with scanning electron microscopy of paraspinous vascular cast specimens after soft tissue maceration and multiple cleaning steps. Image shows arteriolar intramuscular network; counting grid used for vessel diameter distribution analysis within collateral network is superimposed. The inset shows detail of single counting grid, 1 of 35 per image. The vessels shown have diameters of small precapillary arterioles down to 15 to $20 \mu \mathrm{m}$.

circulation in a patient with an aneurysm has undergone modifications that may make its response different from that in a young and healthy pig, reliable data regarding these pathologic changes and their impact on physiology are lacking, so this objection to extrapolating from the pig model remains speculative.

The implications of these findings are quite profound. The studies reinforce the idea that the spinal cord circulation is a longitudinally continuous and flexible system, so that input from any single SA along its length is unlikely to be critical. Thus the quest to identify and reattach the elusive artery of Adamkiewicz is a quixotic endeavor. ${ }^{17}$ Various studies have already demonstrated that the total number of SAs sacrificed during TAAA repair is a more powerful predictor of the risk of paraplegia than is the loss of any specific individual SA. ${ }^{13,26}$ In fact, systematic attempts to identify and reimplant the putative artery of Adamkiewicz thus far have not succeeded in eliminating paraplegia. ${ }^{4,12}$ Furthermore, intercostal patch aneurysms appear to be a significant complication of this approach. ${ }^{27}$

The participation of the subclavian and iliac arteries in the spinal cord perfusion network has been confirmed in previous studies, and the explanation for their physiologic importance is readily found in the context of the collateral network concept. ${ }^{17,28}$ The related possible collateral pathways from the internal thoracic and epigastric arteries providing reversed anterior to posterior flow through the intercostal and lumbar arteries were not visualized in these studies but probably also contribute collateral flow to the spinal cord and back muscles. The rationale for preserving even distant inputs to the collateral system to ensure spinal cord integrity after SA sacrifice is reinforced by an understanding of the dependence of spinal cord perfusion on this extensive interconnected collateral network.

One of the initially startling but ultimately unsurprising findings of this study is just how dramatically the muscular arterial component dominates the anatomy of the network when compared with the small arteries that feed the spinal cord directly. This is a reminder of the precarious nature of the spinal cord blood supply: despite the powerful physiologic mechanisms that are present to safeguard the integrity of spinal cord perfusion, cord blood supply can be seriously threatened by steal phenomena. The anatomic imbalance between the vascular inputs to muscle and spinal cord gives us a clear rationale for being meticulous about minimizing the activity of paravertebral muscles during and immediately after TAAA surgery. This can be effected by liberal use of anesthesia and muscle relaxants and by insistence on at least moderate hypothermia, which dramatically reduces metabolic rate in both muscle and spinal cord and is known to prolong spinal cord ischemic tolerance. Steal from the spinal cord circulation because of demand from muscles is a potent postoperative threat that needs to be added to an already developed awareness of the intraoperative danger of steal from bleeding from open intercostal or lumbar arteries. The threat of steal is particularly relevant 

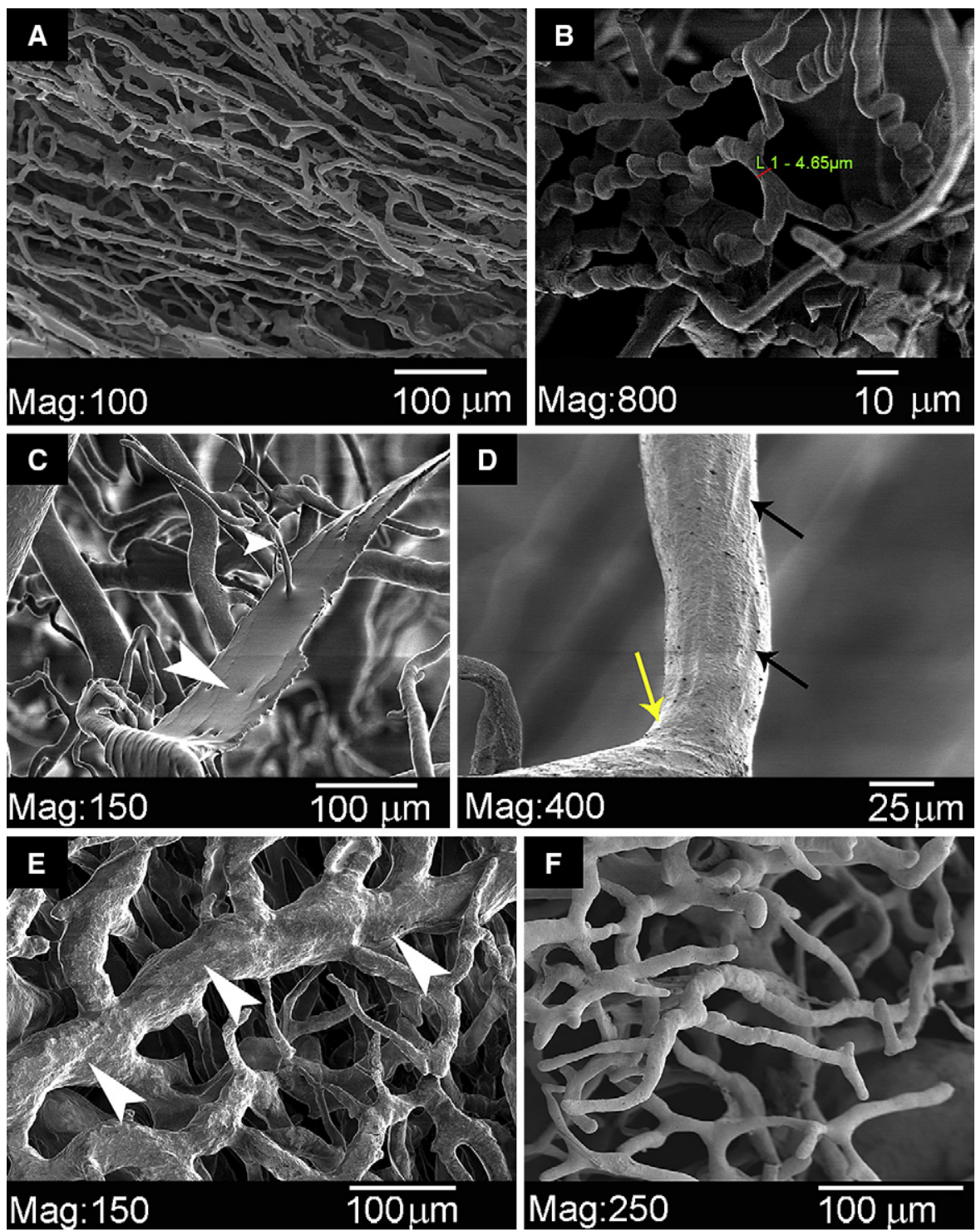

FIGURE 6. Microanatomy of the collateral network. An overview of casts of paraspinous vascular structures. A, Capillary micromesh. B, Detail of typical corkscrew-shaped capillaries. C, Artifact of acrylic resin that has leaked through a damaged vessel wall (white arrowheads). D, Endothelial nuclear imprints on a precapillary arteriole (arrows). E, Network of venules. F, Arteriolar network.

during the first 12 hours after SA sacrifice, when critical spinal cord ischemia most often occurs. ${ }^{24}$

Various adjuncts, such as somatosensory- and motorevoked potential monitoring and cerebrospinal fluid drainage, are currently being used to maximize spinal cord protection during open and endovascular TAAA repair, and they have succeeded in reducing the rate of spinal cord injury. ${ }^{14,16,29-31}$ Although the rate of paraplegia and paraparesis after TAAA repair has declined significantly during the past decade, however, spinal cord injury remains a uniquely devastating complication, the elimination of which has a high priority in many aortic centers. The recent trend toward an increase in the proportion of cases of delayed rather than immediate neurologic injury after surgery for TAAA has highlighted the particular vulnerability of spinal cord perfusion during the first 24 postoperative hours, a time when monitoring of spinal cord function is difficult. ${ }^{24}$ The precariousness of spinal cord perfusion during the early hours after surgery has been documented both in the pig model and in patients by direct pressure recordings from vessels in the collateral circuit; this measurement of spinal cord perfusion pressure is a relatively recent and potentially useful additional monitoring technique. ${ }^{18,19,23,24}$ Ways of minimizing demand from muscles competing for a share of reduced collateral network flow after TAAA repair-such as postponing 


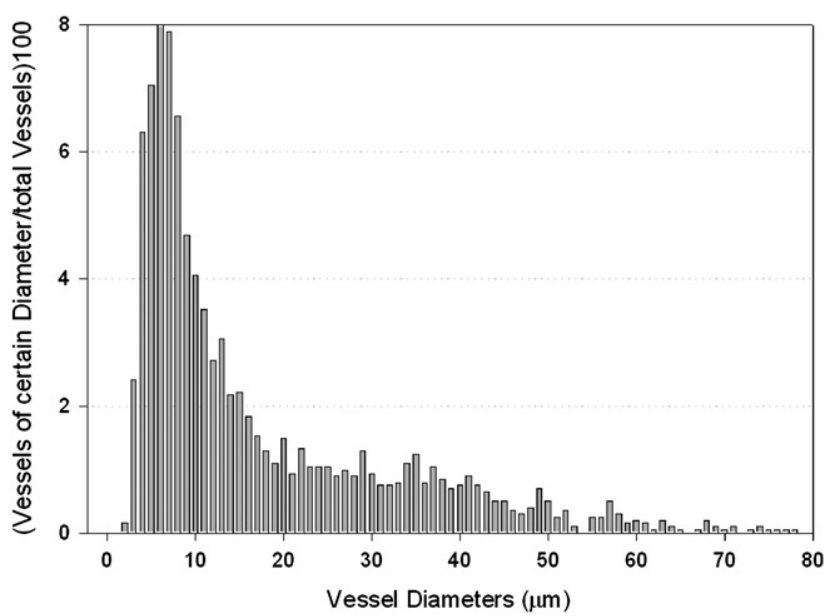

FIGURE 7. Size distribution of capillary and arterioles within the paraspinous collateral network. The graph shows the distribution of vessels of different diameters (up to $80 \mu \mathrm{m}$ ) within the paraspinous vascular network. The number of times vessel of given a diameter was measured is shown as a percentage of all analyzed vessels $(n=2030$ total $)$.

rewarming and inhibiting shivering - may prove effective in improving spinal cord perfusion during this vulnerable early postoperative interval and may help to reduce the occurrence of delayed paraplegia.

The importance of the venous circulation within the spinal canal is also apparent from our current anatomic studies (Figure 3), which show prominent epidural venous channels. Previous clinical observations have suggested that elevated venous pressures can interfere with adequate spinal cord perfusion, ${ }^{24}$ and certainly the cast pictures make it seem plausible that distended epidural veins within the fixed constraints of the spinal canal could physically obstruct the small arteries in addition to the direct hemodynamic effect of reducing net perfusion pressure.

Although the cast studies thus emphasize vulnerabilities associated with spinal cord perfusion, they also provide reason for optimism with regard to the eventual success of endovascular therapy for extensive TAAA. The existence of a continuous network with multiple potential sources of inflow-rather than the traditional view of a system that depends on fixed sources that may fall within a region of aortic pathology requiring resection or exclusion - should enable preservation of spinal cord integrity by manipulation of the existing vascular collateral network without requiring technologic solutions to restore lost segmental sources of input. Monitoring of pressures within the collateral network suggests that precariously low perfusion pressures only prevail for 24 to 72 hours postoperatively, with return to preoperative levels of perfusion thereafter. ${ }^{18,32}$ Further studies in this promising pig model should clarify how the vascular collateral network compensates to provide a stable increase in spinal cord blood flow, and may furnish clues for shortening the interval of postoperative vulnerability during which, at present at least, spinal cord ischemia sometimes results in delayed paraplegia.

\section{CONCLUSIONS}

Cast studies of the perfusion of the spinal cord confirm the existence of a continuous collateral arteriolar network feeding directly and indirectly into the ASA along its entire length. The network is dominated by the rich vasculature of the paraspinous muscles and features multiple longitudinal interconnections as well as input from the intersegmental, subclavian, and iliac arteries.

\section{References}

1. Heinemann MK, Brassel F, Herzog T, Dresler C, Becker H, Borst HG. The role of spinal angiography in operations on the thoracic aorta: myth or reality? Ann Thorac Surg. 1998;65:346-51.

2. Kieffer E, Richard T, Chiras J, Godet G, Cormier E. Preoperative spinal cord arteriography in aneurysmal disease of the descending thoracic and thoracoabdominal aorta: preliminary results in 45 patients. Ann Vasc Surg. 1989;3: 34-46.

3. Williams GM, Perler BA, Burdick JF, Osterman FA Jr, Mitchell S, Merine D, et al. Angiographic localization of spinal cord blood supply and its relationship to postoperative paraplegia. J Vasc Surg. 1991;13:23-33; discussion 35.

4. Williams GM, Roseborough GS, Webb TH, Perler BA, Krosnick T. Preoperative selective intercostal angiography in patients undergoing thoracoabdominal aneurysm repair. J Vasc Surg. 2004;39:314-21.

5. Kawaharada N, Morishita K, Fukada J, Yamada A, Muraki S, Hyodoh H, et al. Thoracoabdominal or descending aortic aneurysm repair after preoperative demonstration of the Adamkiewicz artery by magnetic resonance angiography. Eur J Cardiothorac Surg. 2002;21:970-4.

6. Lazorthes G, Poulhes J, Bastide G, Roulleau J, Chancholle AR. [Research on the arterial vascularization of the medulla; applications to medullary pathology]. Bull Acad Natl Med. 1957;141:464-77. French.

7. Lazorthes G, Poulhes J, Bastide G, Roulleau J, Chancholle AR. [Arterial vascularization of the spine; anatomic research and applications in pathology of the spinal cord and aorta]. Neurochirurgie. 1958;4:3-19. French.

8. Lazorthes G, Gouaze A, Zadeh JO, Santini JJ, Lazorthes Y, Burdin P. Arterial vascularization of the spinal cord. J Neurosurg. 1971;35:253-62.

9. Adamkiewicz A. Die Blutgefaesse des menschlichen Rueckenmarks. S B Heidelberg Akad Wiss. 1882; Theil I+II(85):101-30.

10. Adams HD, Van Geertruyden HH. Neurologic complications of aortic surgery. Ann Surg. 1956;144:574-610.

11. Svensson LG, Hess KR, Coselli JS, Safi HJ. Influence of segmental arteries, extent, and atriofemoral bypass on postoperative paraplegia after thoracoabdominal aortic operations. J Vasc Surg. 1994;20:255-62.

12. Acher CW, Wynn MM, Mell MW, Tefera G, Hoch JR. A quantitative assessment of the impact of intercostal artery reimplantation on paralysis risk in thoracoabdominal aortic aneurysm repair. Ann Surg. 2008;248:529-40.

13. Safi HJ, Miller CC 3rd, Carr C, Iliopoulos DC, Dorsay DA, Baldwin JC. Importance of intercostal artery reattachment during thoracoabdominal aortic aneurysm repair. J Vasc Surg. 1998;27:58-66; discussion -8.

14. Cambria RP, Davison JK, Carter C, Brewster DC, Chang Y, Clark KA, et al. Epidural cooling for spinal cord protection during thoracoabdominal aneurysm repair: A five-year experience. J Vasc Surg. 2000;31:1093-102.

15. Griepp RB, Ergin MA, Galla JD, Lansman S, Khan N, Quintana C, et al. Looking for the artery of Adamkiewicz: a quest to minimize paraplegia after operations for aneurysms of the descending thoracic and thoracoabdominal aorta. J Thorac Cardiovasc Surg. 1996;112:1202-15.

16. Etz CD, Halstead JC, Spielvogel D, Shahani R, Lazala R, Homann TM, et al. Thoracic and thoracoabdominal aneurysm repair: is reimplantation of spinal cord arteries a waste of time? Ann Thorac Surg. 2006;82:1670-7.

17. Griepp RB, Griepp EB. Spinal cord perfusion and protection during descending thoracic and thoracoabdominal aortic surgery: the collateral network concept. Ann Thorac Surg. 2007;83:S865-9; discussion S90-2.

18. Etz CD, Homann TM, Plestis KA, Zhang N, Luehr M, Weisz DJ, et al. Spinal cord perfusion after extensive segmental artery sacrifice: can paraplegia be prevented? Eur J Cardiothorac Surg. 2007;31:643-8. 
19. Etz CD, Homann TM, Luehr M, Kari FA, Weisz DJ, Kleinman G, et al. Spinal cord blood flow and ischemic injury after experimental sacrifice of thoracic and abdominal segmental arteries. Eur J Cardiothorac Surg. 2008;33: 1030-8.

20. Strauch JT, Lauten A, Zhang N, Wahlers T, Griepp RB. Anatomy of spinal cord blood supply in the pig. Ann Thorac Surg. 2007;83:2130-4.

21. Lazorthes G, Gouaze A, Zadeh JO, Santini JJ, Lazorthes Y, Burdin P. Arterial vascularization of the spinal cord: recent studies of the anastomotic substitution pathways. J Neurosurg. 1971;35:253-62.

22. Etz CD, Homann TM, Luehr M, Kari FA, Weisz DJ, Kleinman G, et al. Spinal cord blood flow and ischemic injury after experimental sacrifice of thoracic and abdominal segmental arteries. Eur J Cardiothorac Surg. 2008;33:1030-8.

23. Etz CD, Di Luozzo G, Zoli S, Lazala R, Plestis KA, Bodian CA, et al. Direct spinal cord perfusion pressure monitoring in extensive distal aortic aneurysm repair. Ann Thorac Surg. 2009;87:1764-74.

24. Etz CD, Luehr M, Kari FA, Bodian CA, Smego D, Plestis KA, et al. Paraplegia after extensive thoracic and thoracoabdominal aortic aneurysm repair: does critical spinal cord ischemia occur postoperatively? J Thorac Cardiovasc Surg. 2008; 135:324-30.

25. Crock HV, Yoshizawa H. The blood supply of the lumbar vertebral column. Clin Orthop Relat Res. 1976;115:6-21.
26. Coselli JS, LeMaire SA, de Figueiredo LP, Kirby RP. Paraplegia after thoracoabdominal aortic aneurysm repair: is dissection a risk factor? Ann Thorac Surg. 1997;63:28-36.

27. Kulik A, Allen BT, Kouchoukos NT. Incidence and management of intercostal patch aneurysms after repair of thoracoabdominal aortic aneurysms. $J$ Thorac Cardiovasc Surg. 2009;138:352-8.

28. Strauch JT, Spielvogel D, Lauten A, Zhang N, Shiang H, Weisz D, et al. Importance of extrasegmental vessels for spinal cord blood supply in a chronic porcine model. Eur J Cardiothorac Surg. 2003;24:817-24.

29. Estrera AL, Rubenstein FS, Miller CC 3rd, Huynh TT, Letsou GV, Safi HJ. Descending thoracic aortic aneurysm: surgical approach and treatment using the adjuncts cerebrospinal fluid drainage and distal aortic perfusion. Ann Thorac Surg. 2001;72:481-6.

30. Coselli JS, LeMaire SA, Schmittling ZC, Koksoy C. Cerebrospinal fluid drainage in thoracoabdominal aortic surgery. Semin Vasc Surg. 2000;13:308-14.

31. Weigang E, Hartert M, von Samson P, Sircar R, Pitzer K, Genstorfer J, et al. Thoracoabdominal aortic aneurysm repair: interplay of spinal cord protecting modalities. Eur J Vasc Endovasc Surg. 2005;30:624-31.

32. Etz CD, Di Luozzo G, Zoli S, Lazala R, Plestis KA, Bodian CA, et al. Direct spinal cord perfusion pressure monitoring in extensive distal aortic aneurysm repair. Ann Thorac Surg. 2009;87:1764-74. 